\title{
AVALIAÇÃO MOLECULAR E QUÍMICA DA PFAFFIA SPP. (GINSENG- BRASILEIRO) COMERCIALIZADO NO MERCADO BRASILEIRO POR DNA BARCODING E CROMATOGRAFIA EM CAMADA DELGADA
}

\author{
Natan Silva Matos ${ }^{1}$ \\ Winner Duque Rodrigues ${ }^{2}$ \\ Verônica Luiza Silveira Fialho ${ }^{3}$ \\ Rayssa Amaral Passamani ${ }^{4}$ \\ Juliana Aparecida Severi ${ }^{5}$ \\ Greiciane Gaburro Paneto ${ }^{6}$
}

Resumo: Plantas da espécie Pfaffia são amplamente comercializadas em território nacional e são popularmente conhecidas como Ginseng-brasileiro. Porém, a falta de identificação correta das espécies comercializadas tem gerado fraudes no comércio e expondo a população ao risco, fazendo-se necessário desenvolvimento de novas metodologias de identificação. Nesse projeto, identificou-se geneticamente, utilizando o código de barras de DNA, e quimicamente, utilizando a técnica de Cromatografia em Camada Delgada (CCD) espécimes de Ginseng-brasileiro vendidas no mercado nacional e comparaou com espécimes de referências botanicamente identificadas. Foi possível identificar fraude na venda dos fitoterápicos em questão em pelo menos três amostras comerciais, as quais continham uma espécie diferente da descrita no rótulo. As metodologias de análise por CCD e DNA barcoding foram complementares, e podem ser propostas como alternativa no controle de qualidade destes fitoterápicos.

Palavras-chave: DNA barcoding. CCD; Ginseng-brasileiro; ITS; Pfaffia spp.

\footnotetext{
${ }^{1}$ Farmácia/Universidade Federal do Espirito Santo, Brasil. E-mail: natan.matos@hotmail.com.

2 Farmácia/Universidade Federal do Espirito Santo, Brasil. E-mail: winnerduque@gmail.com.

${ }^{3}$ Farmácia/Universidade Federal do Espirito Santo, Brasil. E-mail: veronicaluizasilveira@hotmail.com.

${ }^{4}$ Farmácia/Universidade Federal do Espirito Santo, Brasil. E-mail: ra_passamani@hotmail.com.

5 Ciências Farmacêuticas/Universidade Estadual Paulista Júlio de Mesquita Filho, Brasil. E-mail: severijuliana@gmail.com.

${ }^{6}$ Biociências e Biotecnologias aplicadas a Farmácia/ Universidade Estadual Paulista Júlio de Mesquita Filho, Brasil. E-mail: ggpaneto@gmail.com.
} 